\title{
SHARP INEQUALITIES FOR THE NUMERICAL RADIUS OF HILBERT SPACE OPERATORS AND OPERATOR MATRICES
}

\author{
Pintu Bhunia, Kallol Paul and Raj Kumar NayaK
}

Abstract. We present new upper and lower bounds for the numerical radius of a bounded linear operator defined on a complex Hilbert space, which improve on the existing bounds. Among many other inequalities proved in this article, we show that for a non-zero bounded linear operator $T$ on a complex Hilbert space $H$,

$$
w(T) \geqslant \frac{\|T\|}{2}+\frac{m\left(T^{2}\right)}{2\|T\|},
$$

where $w(T)$ is the numerical radius of $T$ and $m\left(T^{2}\right)$ is the Crawford number of $T^{2}$. This substantially improves on the existing inequality $w(T) \geqslant \frac{\|T\|}{2}$. We also obtain some upper and lower bounds for the numerical radius of operator matrices and illustrate with numerical examples that these bounds are better than the existing bounds.

Mathematics subject classification (2010): Primary 47A12; Secondary 47A63, 47A30. Keywords and phrases: Numerical radius, operator norm, operator matrix, Hilbert space.

\section{REFERENCES}

[1] S. BAG, P. BhUNIA AND K. PAUl, Bounds of numerical radius of bounded linear operator using $t$-Aluthge transform, Math. Inequal. Appl. 23 (3) (2020) 991-1004.

[2] S. J. Bernau and F. Smithies, A note on normal operators, Proc. Cambridge Philos. Soc. 59 (1963) 727-729.

[3] R. Bhatia, Matrix Analysis, Springer, New York, 1997.

[4] P. BHUNIA, S. BAG AND K. PAUL, Numerical radius inequalities and its applications in estimation of zeros of polynomials, Linear Algebra Appl. 573 (2019) 166-177.

[5] P. BhUNIA, S. BAG AND K. PAUL, Numerical radius inequalities of operator matrices with applications, Linear Multilinear Algebra, (2019), https://doi.org/10.1080/03081087.2019.1634673.

[6] S. S. DRAGOMIR, Inequalities for the numerical radius of linear operators in Hilbert spaces, Springer, 2013.

[7] H. Guelfen And F. Kittaneh, On numerical radius inequalities for operator matrices, Numer. Funct. Anal. Optim. 40 (2019) 1231-1241.

[8] K. E. Gustafson and D. K. M. RaO, Numerical range, Springer, New York, 1997.

[9] O. Hirzallah, F. Kittaneh AND K. Shebrawi, Numerical radius inequalities for certain $2 \times 2$ operator matrices, Integral Equations Operator Theory 71 (2011) 129-147.

[10] J. C. Hou AND H. K. DU, Norm inequalities of positive operator matrices, Integral Equations Operator Theory 22 (1995) 281-294.

[11] F. Kittaneh, M. S. Moslehian and T. Yamazaki, Cartesian decomposition and numerical radius inequalities, Linear Algebra Appl. 471 (2015) 46-53.

[12] F. KitTANeH, Numerical radius inequalities for Hilbert spaces operators, Studia Math. 168 (1) (2005) 73-80.

[13] K. PAUL AND S. BAG, Estimation of bounds for the zeros of a polynomial using numerical radius, Appl. Math. Comput. 222 (2013) 231-243. 
[14] K. PAUL AND S. BAG, On the numerical radius of a matrix and estimation of bounds for zeros of a polynomial, Int. J. Math. Math. Sci. 2012 (2012) Article Id 129132, https://doi.org/10.1155/2012/129132.

[15] K. SHEBRAWI, Numerical radius inequalities for certain $2 \times 2$ operator matrices II, Linear Algebra Appl. $\mathbf{5 2 3}$ (2017) 1-12.

[16] T. YAMAZAKI, On upper and lower bounds of the numerical radius and an equality condition, Studia Math. 178 (1) (2007) 83-89. 